\title{
Development and application of a reactive plume-in-grid model: evaluation over Greater Paris
}

\author{
I. Korsakissok ${ }^{1,2}$ and V. Mallet ${ }^{2,1}$ \\ ${ }^{1}$ CEREA, Joint Research Laboratory, ENPC/EDF R\&D, Université Paris Est, 6-8 avenue Blaise Pascal, Cité Descartes, \\ 77455 Champs-sur-Marne, Marne la Vallée Cedex 2, France \\ ${ }^{2}$ INRIA, Paris-Rocquencourt Research Center, B.P. 105, 78153 Le Chesnay Cedex, France
}

Received: 5 February 2010 - Published in Atmos. Chem. Phys. Discuss.: 22 February 2010

Revised: 23 June 2010 - Accepted: 6 September 2010 - Published: 22 September 2010

\begin{abstract}
Emissions from major point sources are badly represented by classical Eulerian models. An overestimation of the horizontal plume dilution, a bad representation of the vertical diffusion as well as an incorrect estimate of the chemical reaction rates are the main limitations of such models in the vicinity of major point sources. The plume-in-grid method is a multiscale modeling technique that couples a local-scale Gaussian puff model with an Eulerian model in order to better represent these emissions. We present the plume-in-grid model developed in the air quality modeling system Polyphemus, with full gaseous chemistry. The model is evaluated on the metropolitan Île-de-France region, during six months (summer 2001). The subgrid-scale treatment is used for 89 major point sources, a selection based on the emission rates of $\mathrm{NO}_{\mathrm{x}}$ and $\mathrm{SO}_{2}$. Results with and without the subgrid treatment of point emissions are compared, and their performance by comparison to the observations on measurement stations is assessed. A sensitivity study is also carried out, on several local-scale parameters as well as on the vertical diffusion within the urban area.

Primary pollutants are shown to be the most impacted by the plume-in-grid treatment. $\mathrm{SO}_{2}$ is the most impacted pollutant, since the point sources account for an important part of the total $\mathrm{SO}_{2}$ emissions, whereas $\mathrm{NO}_{\mathrm{x}}$ emissions are mostly due to traffic. The spatial impact of the subgrid treatment is localized in the vicinity of the sources, especially for reactive species $\left(\mathrm{NO}_{\mathrm{x}}\right.$ and $\left.\mathrm{O}_{3}\right)$. Ozone is mostly sensitive to the time step between two puff emissions which influences the in-plume chemical reactions, whereas the almost-passive species $\mathrm{SO}_{2}$ is more sensitive to the injection time, which determines the duration of the subgrid-scale treatment.
\end{abstract}

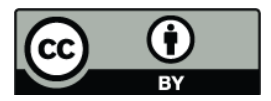

Correspondence to: I. Korsakissok (korsakissok@cerea.enpc.fr)
Future developments include an extension to handle aerosol chemistry, and an application to the modeling of line sources in order to use the subgrid treatment with road emissions. The latter is expected to lead to more striking results, due to the importance of traffic emissions for the pollutants of interest.

\section{Introduction}

Traditional Eulerian gridded models suffer from several limitations when applied to the dispersion of elevated point emissions, such as emissions from power plant stacks. First, a point emission is assumed to immediately mix within the cell volume, whereas a typical point-source plume does not expand to the size of the grid cell for a substantial time period (depending on the resolution, and on the meteorological situation). Besides, the K-theory approach often used in Eulerian models does not properly represent the diffusion in the vicinity of the source (Maryon and Buckland, 1995). In addition, the incorrect representation of concentrations within the plume leads to a poor estimation of the chemical reaction rates, in the case of reactive plumes. As a consequence, subgrid-scale modeling techniques for point sources have been developed and applied over the years. These socalled plume-in-grid models consist in embedding a localscale model (usually a Gaussian plume or puff model) within an Eulerian 3-D model, in order to treat the plumes at subgrid scale, thus eliminating some of the aforementioned errors. Such a model was first developed by Seigneur et al. (1983). Other models have been used for photochemical applications since then (Gillani, 1986; Morris et al., 1991; Kumar and Russell, 1996; Godowitch, 2004; Karamchandani et al., 2002; Vijayaraghavan et al., 2006), as well as for passive tracers (Brandt, 1998). The plume-in-grid model

Published by Copernicus Publications on behalf of the European Geosciences Union. 
employed here has been developed on the air quality modeling system Polyphemus (Mallet et al., 2007). The aim is to provide an easy-to-use, modular model, fit for applications from regional to continental scales, and both for reactive and non-reactive pollutants. It was already described and applied at continental scale for passive tracers (Korsakissok and Mallet, 2010). The model has been extended to handle full gaseous chemistry, and is therefore evaluated in this study for photochemical applications.

The chosen application domain is the metropolitan Île-deFrance region, with Paris at the center of the domain. Regional air quality modeling focused on large urban areas is an important topic, both for decision support (e.g., for emission abatement policies) and to assess impact on health and ecosystems. Île-de-France contains many point source emissions, mainly industrial stacks. This application is somewhat different from previous plume-in-grid studies: the modeling domain is smaller and there is a higher number of point sources (89), but with lower emission rates. For instance, in Vijayaraghavan et al. (2006), the application domain was California. The 10 major point sources selected for the application emitted slightly more $\mathrm{NO}_{\mathrm{x}}$ emission rate than the 89 point sources retained here. In our case, the simulations are carried out for six months, during summer 2001. Our analysis is based on both on global results for the whole period, and on a few selected days of interest. This approach differs from that of many other studies, where only some short ozone episodes were selected.

The aim of the study is (1) to determine the plume-in-grid impact, in terms of statistics as well as spatial variability, in the case of a high number of point sources well distributed over an urban area, and (2) to give insights on the sensitivity to various parameters, and on the relevant spatial and temporal scales. Section 2 describes the plume-in-grid model, with an emphasis on the chemistry within the puffs, and Sect. 3 details the application domain and the modeling set-up. In Sect. 4, the plume-in-grid impact is assessed, both on performance indicators and in terms of spatial variability. In Sect. 5, we present a sensitivity analysis, focused on the impact of the vertical diffusion and on the influence of temporal parameters.

\section{Model overview}

The plume-in-grid model presented here couples, on the Polyphemus platform, the Gaussian puff model (Korsakissok and Mallet, 2009) with the Eulerian model Polair3D (Boutahar et al., 2004). It has already been described and evaluated for passive tracers at continental scale in Korsakissok and Mallet (2010). In this section, the Gaussian puff model parameterizations, and the coupling method, are only briefly described (Sect. 2.1), with an emphasis on the spatial and temporal scales of the model (Sect. 2.2). We also focus on the description of the chemistry within the puffs (Sect. 2.3).

\subsection{Coupling}

The Gaussian puff model (Korsakissok and Mallet, 2009) represents a continuous point source emission as a series of puffs with a Gaussian shape in the three directions. Each puff transports a given quantity of each of the emitted species. The puffs move independently from one another, since the speed and direction of a puff are determined by the wind at its center (interpolated from the Eulerian fields). Each puff's size increases with turbulence, and is determined by the Gaussian standard deviations in all three directions: $\sigma_{x}$ (downwind), $\sigma_{y}$ (crosswind) and $\sigma_{z}$ (vertical). In the Gaussian puff model of Polyphemus, three empirical parameterizations may be used to compute the Gaussian standard deviations: Briggs's, Doury's and similarity-theory.

In the plume-in-grid model, several point source emissions are treated by the Gaussian puff model while other sources, namely diffuse area emissions, are managed by Polair3D. The two models exchange information at each time step. On one way, background data (meteorological data, concentrations, deposition velocities...) is retrieved from the Eulerian model and bi-linearly interpolated at the center of each puff. On the other way, the concentrations handled by the Gaussian model are eventually injected into the Eulerian model: the puff's mass is distributed within the cells vertically covered by the puff.

\subsection{Spatial and temporal scales}

Two particular temporal scales are focused on, since they are key to the plume-in-grid modeling, and determine the total number of puffs handled by the model at each time step:

- the time step between two puff emissions $\Delta t_{\text {puff, }}$

- the time when a given puff is transferred to the Eulerian model $t_{\text {inj. }}$.

The full chemical mechanism is applied within each puff, and the computational time increases accordingly. These two parameters have therefore to be chosen carefully, ensuring a reasonable computational time as well as a physically consistent modeling. The model sensitivity to these parameters is assessed in Sect. 5, and they are briefly described below.

\subsubsection{Time step between two puffs}

A continuous plume is well represented if there is a sufficient overlap between two consecutive puffs in the downwind direction. This is particularly important for reactive species, since reactions occur within each puff and within the overlapping puffs. Underestimating the overlap volume induces changes in the chemistry. As a consequence, the time step between two puff emissions, noted $\Delta t_{\text {puff }}$, needs to be small enough. In practice, this condition is fulfilled at time $t$, for 
two successive puffs emitted at times $t_{i}$ and $t_{i+1}=t_{i}+\Delta t_{\text {puff }}$ respectively, if:

$\sigma_{x}\left(t-t_{i}\right)+\sigma_{x}\left(t-t_{i+1}\right) \geq \frac{u}{C_{y}} \Delta t_{\mathrm{puff}}$,

where $u$ is the wind speed at time $t$ and at the puffs' locations, and the puffs' standard deviations are $\sigma_{x}\left(t-t_{i}\right)$ and $\sigma_{x}\left(t-t_{i+1}\right)$ in the $x$ direction. It therefore depends on the meteorological conditions. $C_{y}$ is the constant which determines the puffs' effective size (in practice $C_{y}=2$ ). In the present case-study, the time step between two puff emissions is $\Delta t_{\text {puff }}=100 \mathrm{~s}$, to match the Eulerian time step. For a wind speed of $5 \mathrm{~ms}^{-1}$, the overlap condition given in Eq. (1) is therefore fulfilled as soon as $\sigma_{x} \geq 125 \mathrm{~m}$, which in unstable conditions is reached within one or two time steps. In stable situations, the puffs' spread is smaller and the wind speed is lower, so the condition is also fulfilled within a few time steps.

\subsubsection{Injection time}

The criterion to switch from the local-scale to the Eulerian model (so-called "injection time") has to be determined so that the artificial dilution due to the Eulerian model is limited, and the Gaussian model error due to trajectory uncertainties is not too large. It depends on the ratio between the Eulerian cell size and the plume horizontal size, on wind shear, and also on chemistry: for chemically reactive plumes, a puff can be released when its chemical composition does not significantly differ from the background (Vijayaraghavan et al., 2006). In Korsakissok and Mallet (2010), the influence of the injection time was assessed at several grid resolutions, at continental scale. Two criteria were tested: (1) either the puff is transferred after a given travel time, or puff "age", called the injection time $t_{\text {inj }}$, or (2) the puff is transferred as soon has its horizontal size (given by $2 C_{y} \sigma_{y}$ ) is about the cell size. The size criterion gave the best results at fine resolution, but the time criterion was better when the grid resolution was too coarse and the puff size criterion would lead to large transfer times, inducing large errors in the puffs trajectory. An injection time of the order of magnitude of the time for a puff to cross one cell was suggested, with an upper limit of about three hours. At regional scale, for a mean wind speed of about $5 \mathrm{~ms}^{-1}$ and a cell size of $5 \mathrm{~km}$, the injection time would therefore be around 20 minutes, which is used here. This is of the same order of magnitude as the time when the chemical plume regime changes, and becomes closer to the background chemistry (Karamchandani et al., 1998).

\subsection{Chemical coupling}

Each puff transports all species of the chemical mechanism of the Eulerian model. The initial puff quantities of secondary species are obviously equal to zero. Chemistry takes place in the puffs, with the following characteristics:
- the species in one puff $\alpha$ react with each other,

- the species of two overlapping puffs $\alpha$ and $\beta$ react with each other (Appendix A),

- the species in one puff react with the background species. This interaction is detailed below.

In the case of non-linear chemistry (second order reactions), it is necessary to take into account the interaction between the background and the puff species. In the plume-ingrid model, the chemical reactions between the background species are already taken into account in the Eulerian model. Therefore, only the additional perturbation due to the interaction has to be added to the puff quantity. According to Karamchandani et al. (2000), we use the following procedure

1. Add the background concentration $c_{A}^{b}$ to the puff concentration, and compute the chemistry on the total concentration. The rate of disappearance for species $A$, supposing a reaction of type $A+B \rightarrow P$ occurs, is then

$$
\frac{\mathrm{d}\left(c_{A}^{\alpha}+c_{A}^{b}\right)}{\mathrm{dt}}=-k(\underbrace{c_{A}^{\alpha} c_{B}^{\alpha}}_{(1)}+\underbrace{c_{A}^{b} c_{B}^{b}}_{(2)}+\underbrace{c_{A}^{\alpha} c_{B}^{b}+c_{B}^{\alpha} c_{A}^{b}}_{(3)}),
$$

where $k$ is the reaction rate, (1) represents the chemistry between the puff species, (2) is the chemistry between the background species, and (3) is the interaction between the puff and background species.

2. Compute separately the chemistry between background species only. The rate of disappearance of $A$ is then

$$
\frac{\mathrm{d} c_{A}^{b}}{\mathrm{dt}}=-k c_{A}^{b} c_{B}^{b}
$$

3. Subtract the results of the time integration over one time step of the two previous equations. The term (2) in Eq. (2) is taken into account in the background (Eulerian) chemistry, and terms (1) and (3) are carried by the puff.

Since the puff carries the interaction term (term (3) in Eq. 2), it can transport negative concentrations. It occurs when a background species, which was not emitted, is depleted by a reaction that occurs inside the puff. Thus, the puff can be considered as a "perturbation" to the background concentration. The total concentration is obtained by adding the puff's concentration to the background concentration, and is always positive.

A simple example is illustrated in Fig. 1: a plume of NO and $\mathrm{NO}_{2}$ is released at $30 \mathrm{~m}$ above the ground, in a uniform background of $\mathrm{O}_{3}\left(40 \mu \mathrm{g} / \mathrm{m}^{3}\right)$. There are no other emissions, boundary or initial conditions. The total plume mass is the sum of the quantities carried by all existing puffs (that is, without the puffs that have already been injected into 


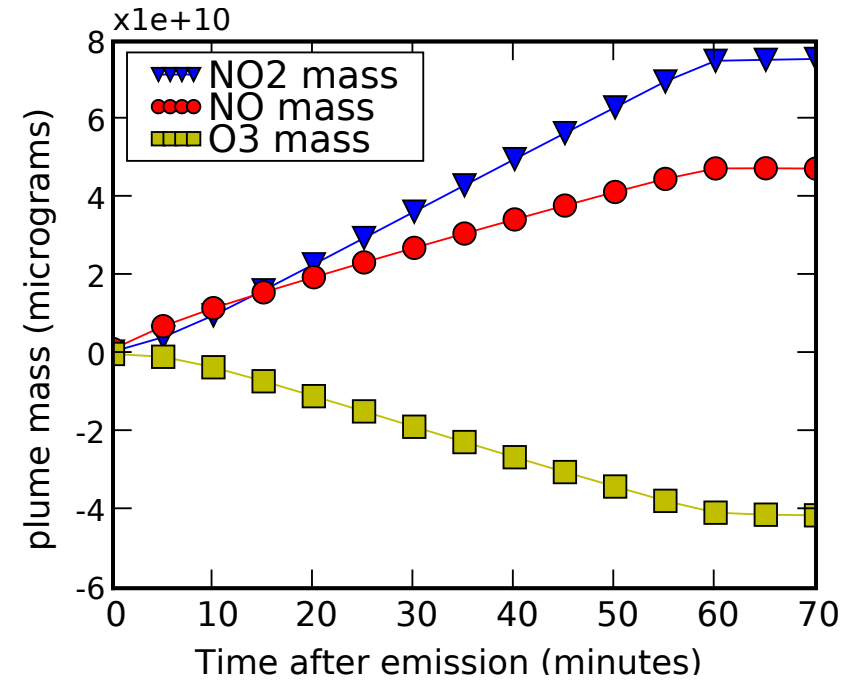

Fig. 1. Plume mass in $\mu$ g for $\mathrm{NO}_{2}, \mathrm{NO}$ and $\mathrm{O}_{3}$ with plume-in-grid. Simulation with one point source of $\mathrm{NO}_{\mathrm{x}}$ in a uniform background of $\mathrm{O}_{3}$.

the Eulerian model). Since the puffs carry a perturbation of the background concentrations, the plume mass of $\mathrm{O}_{3}$ is negative, and represents the amount of ozone that has been titrated. Although the emitted mass of NO is more than twice that of $\mathrm{NO}_{2}$ (emission rates are $21 \mathrm{~g} \mathrm{~s}^{-1}$ and $10 \mathrm{~g} \mathrm{~s}^{-1}$, respectively), the plume mass of $\mathrm{NO}_{2}$ is higher after about ten minutes, due to the titration of $\mathrm{O}_{3}$ by $\mathrm{NO}$ producing $\mathrm{NO}_{2}$. The source is emitting continuously. After one hour, the puffs are transferred into the Eulerian model, and are no longer included in the total plume mass, which therefore becomes almost constant. Figure 2 shows the difference between the $\mathrm{O}_{3}$ concentration profiles, with and without the plume-in-grid treatment for this simple case. $\mathrm{O}_{3}$ concentration is lower within the plume. When using the plume-in-grid model, the $\mathrm{NO}_{\mathrm{x}}$ plume stays longer above the ground, and is more concentrated, than with the Eulerian model. Thus, using a subgrid-scale treatment induces higher $\mathrm{O}_{3}$ concentrations at ground level in the vicinity of the source, and lower inplume concentrations. Farther downwind, the plume touches the ground, inducing lower ground concentrations with the plume-in-grid model.

\section{Application: air quality over Paris region}

\subsection{Modeling set-up}

The plume-in-grid model is applied over Paris region, during 6 months for the year 2001, from 01-04-2001 to 27-09-2001. The simulation set-up is similar to that used in Tombette and Sportisse (2007). The simulation area covers the Îlede-France, and ranges from $1.40^{\circ} \mathrm{E}$ to $3.55^{\circ} \mathrm{E}$ (44 cells) and from $48.10^{\circ} \mathrm{N}$ to $49.20^{\circ} \mathrm{N}$ ( 23 cells) (Fig. 3). The cells size

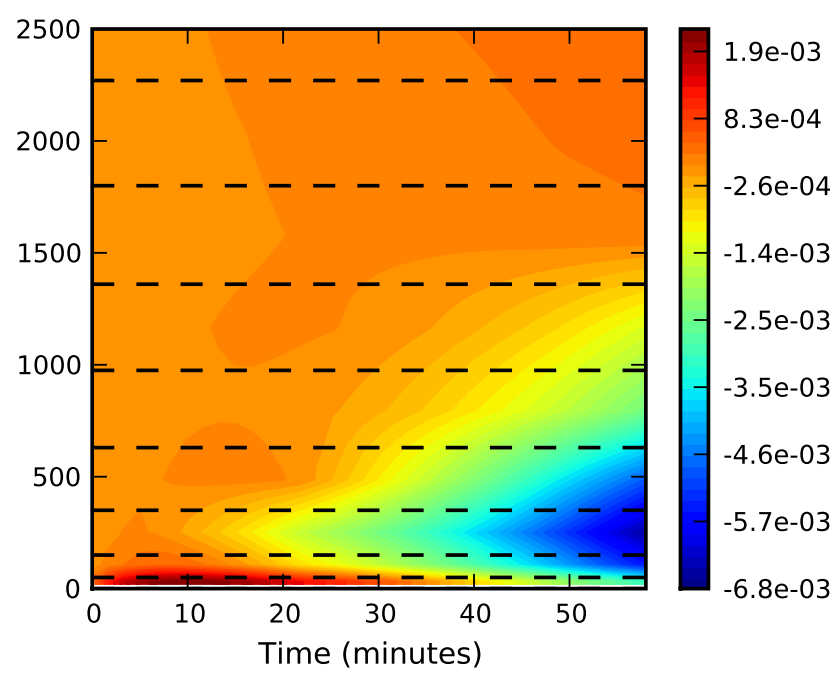

Fig. 2. Vertical profile as a function of time: difference between $\mathrm{O}_{3}$ concentrations averaged over the simulation domain (in $\mu \mathrm{g} \mathrm{m}^{-3}$ ) with and without the subgrid treatment. Simulation with one point source of $\mathrm{NO}_{\mathrm{x}}$ in a uniform background of $\mathrm{O}_{3}$. The dashed lines represent the vertical levels interfaces of the Eulerian model. The vertical levels are indicated in meters above the ground.

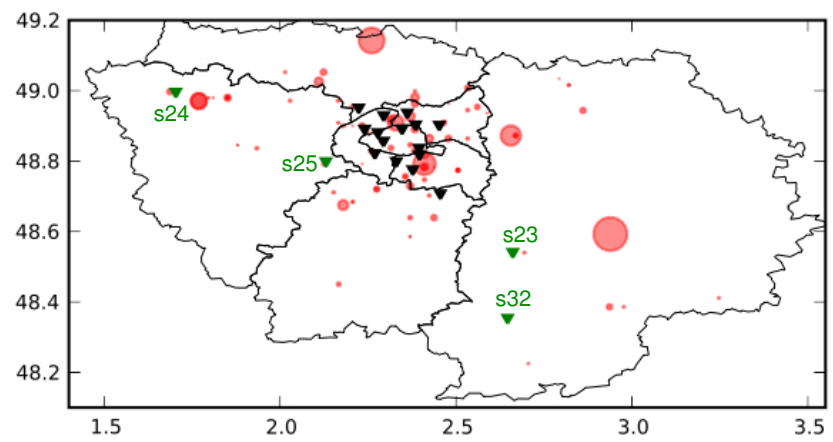

Fig. 3. Measurement stations (triangles), and main point sources, for $\mathrm{SO}_{2}$. The circles areas are proportional to the sources emission rate. The black triangles are urban stations, green triangles are periurban and rural stations (the names of these stations also are indicated).

in longitude and latitude is $0.05^{\circ}$. There are nine vertical levels, up to $2730 \mathrm{~m}$, and the first layer is $50 \mathrm{~m}$ high. The meteorological fields are interpolated from ECMWF fields of resolution $0.36^{\circ}$. The boundary conditions are taken from a simulation over Europe with a resolution of $0.5^{\circ}$. The time step is $100 \mathrm{~s}$, for the Eulerian simulation as well as for the puffs advection and diffusion.

For the vertical diffusion coefficient, we use the TroenMahrt parameterization (Troen and Mahrt, 1986) inside the boundary layer, with a minimal value for $K_{z}$ equal to $0.5 \mathrm{~m}^{2} \mathrm{~s}^{-1}$ over urban areas and $0.2 \mathrm{~m}^{2} \mathrm{~s}^{-1}$ elsewhere. The higher value for urban areas is used to take into account the effects of the urban heat island phenomenon, which increase 


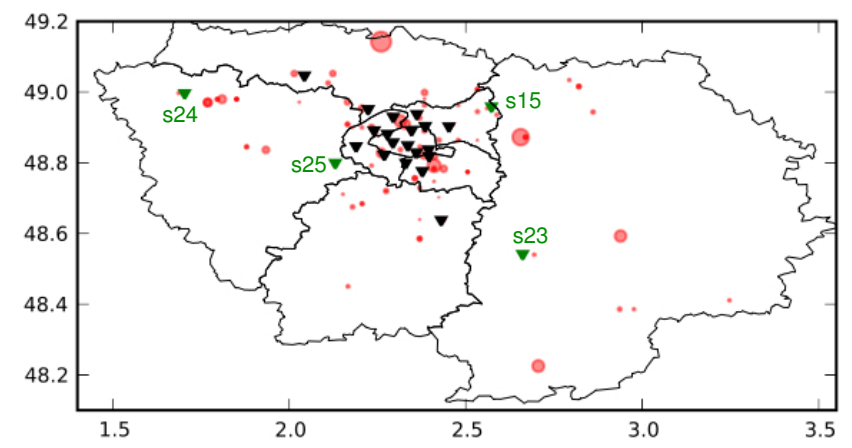

Fig. 4. Measurement stations (triangles), and main point sources, for NO. The circles areas are proportional to the sources emission rate. The black triangles are urban stations, green triangles are periurban and rural stations (the names of these stations also are indicated).

the vertical diffusion. The impact of such a change in the urban vertical diffusion is assessed in Sect. 5.1. The Louis parameterization (Louis, 1979) is used above the boundary layer. Only gas-phase chemistry is taken into account. The Regional Atmospheric Chemistry Mechanism (RACM, Stockwell et al., 1997) is used both in the Eulerian model and in the Gaussian model.

The emissions are taken from the inventory provided by Airparif, which is in charge of the local air quality monitoring, for year 2000. Surface and volume diffuse emissions are interpolated on the simulation grid to be used with the Eulerian model. The data from the major point sources, which amount to 295 sources, are treated separately from the other emissions. For each source, the emission rate is given for all emitted species. Typical profiles provide coefficients, applied to the emission rate, to represent the time evolution of the emission rates during the day cycle. For the plume-ingrid treatment, we selected the sources with an emission rate of $\mathrm{NO}_{\mathrm{x}}$ or $\mathrm{SO}_{2}$ higher than $Q_{\text {min }}=10^{6} \mu \mathrm{g} \mathrm{s}^{-1}$. This provides a selection of 89 point sources to be processed with the plume-in-grid method, the others being treated directly by the Eulerian model. The selected sources account for $94 \%$ of the total $\mathrm{NO}_{\mathrm{x}}$ mass emitted by all the point sources, and $98 \%$ of the total $\mathrm{SO}_{2}$ point emissions. The total emissions originating from point sources, account for about $16 \%$ of the $\mathrm{NO}_{\mathrm{x}}$ emissions and $60 \%$ of the $\mathrm{SO}_{2}$ emissions. Thus, using a special treatment on point sources is not expected to dramatically change the global model performance, except at some near-plume stations. The impact should be higher for $\mathrm{SO}_{2}$, compared to other species. The main sources and the measurement stations are shown for $\mathrm{SO}_{2}$ and NO, Figs. 3 and 4, respectively. We focus here on $\mathrm{NO}_{\mathrm{x}}$ and $\mathrm{SO}_{2}$, but the plumein-grid simulation takes into account all the species emitted by the sources, including VOCs.
The emission inventory provides the location and emission rates of the sources, but the information useful to compute the plume rise (source temperature and ejection velocity, section) was not provided. The plume rise was therefore computed using estimated values of $12 \mathrm{~m} \mathrm{~s}^{-1}$ for the ejection velocity, $100{ }^{\circ} \mathrm{C}$ for the emission temperature and $5 \mathrm{~m}^{2}$ for the chimney section. This corresponds to a plume rise of about $30 \mathrm{~m}$ and up to $100 \mathrm{~m}$ in some cases. The formulae to compute the plume rise are the Briggs formulae with the unstable and neutral breakup formulae added from Hanna and Paine (1989). They are detailed and compared to other parameterizations in Korsakissok and Mallet (2009). Using approximated values for the plume rise computation is an additional source of uncertainties. However, the values of plume rise obtained are comparable to the shift in the source height made in the Eulerian model, where point sources are placed at the center of a vertical layer. For instance, many significant sources have a height between $60 \mathrm{~m}$ and $80 \mathrm{~m}$ and are injected at $100 \mathrm{~m}$ in the Eulerian simulation.

\subsection{Simulations}

Several simulations were carried out, with the configuration detailed in Sect. 3.1.

1. A benchmark simulation with only the gridded model Polair3D, where the selected point sources are treated the same way as the other sources (i.e., processed by the Eulerian model without a plume-in-grid treatment). It is hereafter called the reference simulation,

2. Three simulations where the selected 89 point sources are treated by the plume-in-grid model, one for each Gaussian parameterization (Briggs, Doury, similarity theory), called plume-in-grid simulations,

3. A Polair3D simulation excluding the 89 point sources, referred to as background simulation.

The plume-in-grid simulations are carried out with $t_{\text {inj }}=$ $20 \mathrm{~min}$ and $\Delta t_{\text {puff }}=100 \mathrm{~s}$, as explained in Sect. 2.2. This ensures that the puffs are injected after 12 time steps, which corresponds to 1068 puffs handled by the model. The computational time using the plume-in-grid model with this number of puffs and full gaseous chemistry is between 2 and 3 times the time for the Eulerian simulations. The results from these simulations are detailed in Sect. 4. In addition, several other simulations have been performed for the sensitivity study, and are detailed Sect. 5. 


\section{Impact of plume-in-grid treatment}

\subsection{Plume-in-grid impact on statistics}

\subsubsection{Evaluation criteria}

The performance for the reference simulation and the plumein-grid model is evaluated using hourly surface observations at monitoring locations in the Airparif network.

The indicators used in this study are the root mean square error (RMSE), the correlation (Corr), the mean fractional bias (MFBE) and the mean fractional error (MFGE). In addition, we also use the three indicators recommended for $\mathrm{O}_{3}$ by the US EPA (EPA, 2005): the mean normalized gross error (MNGE), the mean normalized bias (MNBE) and the unpaired peak accuracy (UPA). The last one is the difference between the simulated and observed maximum values at all stations, normalized by the observed maximum.

The suggested model performance goal is a fractional bias within $\pm 30 \%$ (Chang and Hanna, 2004), and a fractional error lower than 50\%. The EPA recommends (EPA, 1991) that $\mathrm{MNGE} \leq 35 \%, \mathrm{MNBE}$ is within $\pm 15 \%$ and UPA is within $\pm 20 \%$. The statistics are computed on all measurement stations where at least $60 \%$ of the observations for the simulation period are available. This amounts to 19 stations for $\mathrm{SO}_{2}$ (Fig. 3), 21 stations for $\mathrm{O}_{3}, 24$ for $\mathrm{NO}$ (Fig. 4) and 26 for $\mathrm{NO}_{2}$, on a total of 48 available measurement stations. To compute the MNGE, MNBE and UPA, it is recommended to use a cutoff for $\mathrm{O}_{3}$ concentrations, in order to select only the highest values. Here, a cutoff value of $30 \mu \mathrm{g} \mathrm{m}^{-3}$ is applied.

\subsubsection{Global statistics}

Table 1 shows the results for hourly concentrations of $\mathrm{SO}_{2}$, $\mathrm{NO}, \mathrm{O}_{3}$ and $\mathrm{NO}_{2}$. In most cases, the model results satisfy the performance criteria given in Sect. 4.1.1 for $\mathrm{O}_{3}$ and $\mathrm{NO}_{2}$. The model does not perform so well for $\mathrm{SO}_{2}$ and $\mathrm{NO}$, which are significantly over-estimated. The results are shown for the reference simulation and for the plume-in-grid model with the three Gaussian parameterizations. For almost all species and indicators, the best results are achieved by the plume-in-grid model with similarity theory. The Briggs parameterization also gives good results, while Doury's is the worst, although better than the reference results most of the time. This is consistent with the good performance of the Briggs and similarity-theory parameterizations at very local scale (up to a few kilometers downwind of the source), shown on Prairie Grass and Kincaid field experiments (Korsakissok and Mallet, 2009). On the contrary, the Doury formulas were fitted on a wider field experiment and gave the best results of the three parameterizations used by the plumein-grid model at continental scale (Korsakissok and Mallet, 2010).

Using a plume-in-grid treatment does not significantly change the global statistics, which was to be expected con-
Table 1. Hourly statistics for the reference simulation with Polair3D ("Reference"), and plume-in-grid simulations, for three Gaussian parameterizations ("Sim.th." stands for similarity theory). The simulation period is 2001-04-01-2001-09-27. The best statistics are highlighted in bold.

\begin{tabular}{lccccc}
\hline Statistic & Obs & Reference & Doury & Briggs & Sim.th. \\
\hline $\mathrm{SO}_{2}$ & & & & & \\
Mean $\left(\mu \mathrm{g} \mathrm{m}^{-3}\right)$ & 6.20 & 13.76 & 12.59 & 12.24 & $\mathbf{1 1 . 9 8}$ \\
RMSE & & 13.08 & 12.16 & 12.06 & $\mathbf{1 1 . 8 8}$ \\
Correlation & & $\mathbf{0 . 3 5}$ & 0.34 & 0.33 & 0.31 \\
MFBE & & 0.66 & 0.59 & 0.55 & $\mathbf{0 . 5 5}$ \\
MFGE & & 0.81 & 0.77 & 0.76 & $\mathbf{0 . 7 5}$ \\
NO & & & & \\
Mean $\left(\mu \mathrm{g} \mathrm{m}^{-3}\right)$ & 10.42 & 20.93 & 20.26 & 19.94 & $\mathbf{1 9 . 6 4}$ \\
RMSE & & 33.08 & 32.44 & 32.37 & $\mathbf{3 1 . 6 2}$ \\
Correlation & & $\mathbf{0 . 4 7}$ & $\mathbf{0 . 4 7}$ & $\mathbf{0 . 4 7}$ & 0.46 \\
MFBE & & 0.41 & 0.39 & 0.36 & $\mathbf{0 . 3 6}$ \\
MFGE & & 0.94 & 0.93 & 0.92 & $\mathbf{0 . 9 2}$ \\
$\mathrm{O}_{3}$ & & & & \\
Mean $\left(\mu \mathrm{g} \mathrm{m}^{-3}\right.$ ) & 56.87 & 40.24 & 40.58 & 40.94 & $\mathbf{4 1 . 0 5}$ \\
RMSE & & 30.58 & 30.41 & 30.22 & $\mathbf{3 0 . 1 8}$ \\
Correlation & & $\mathbf{0 . 6 8}$ & $\mathbf{0 . 6 8}$ & $\mathbf{0 . 6 8}$ & $\mathbf{0 . 6 8}$ \\
MFBE & & -0.46 & -0.45 & $-\mathbf{0 . 4 4}$ & $-\mathbf{0 . 4 4}$ \\
MFGE & & 0.47 & 0.46 & 0.46 & $\mathbf{0 . 4 5}$ \\
MNBE & & -0.34 & $-\mathbf{0 . 3 3}$ & $-\mathbf{0 . 3 3}$ & $-\mathbf{0 . 3 3}$ \\
MNGE & & 0.35 & 0.35 & $\mathbf{0 . 3 4}$ & $\mathbf{0 . 3 4}$ \\
UPA & & -0.21 & -0.21 & -0.21 & $-\mathbf{0 . 2 0}$ \\
NO & & & & \\
Mean $\left(\mu \mathrm{g} \mathrm{m}^{-3}\right.$ ) & 34.64 & 35.84 & 35.47 & 35.28 & $\mathbf{3 5 . 2 3}$ \\
RMSE & & $\mathbf{2 0 . 5 7}$ & 20.64 & 20.74 & 20.81 \\
Correlation & & $\mathbf{0 . 5 8}$ & 0.57 & 0.57 & 0.57 \\
MFBE & & 0.06 & 0.05 & $\mathbf{0 . 0 4}$ & $\mathbf{0 . 0 4}$ \\
MFGE & & $\mathbf{0 . 4 7}$ & $\mathbf{0 . 4 7}$ & $\mathbf{0 . 4 7}$ & $\mathbf{0 . 4 7}$ \\
\hline
\end{tabular}

sidering (1) the relatively small contribution of point sources in the total emissions, and (2) that statistics are computed on background stations, which are not located in the vicinity of major point sources. However, there is a clear improvement for $\mathrm{NO}$ and $\mathrm{SO}_{2}$. The RMSE is reduced by $9 \%$ in the case of $\mathrm{SO}_{2}$ and $4.5 \%$ for NO. On the contrary, the results for $\mathrm{NO}_{2}$ and $\mathrm{O}_{3}$ are globally unchanged. This tends to show that the use of a subgrid-scale treatment of emissions has more impact on the primary pollutants than on secondary species. Moreover, the point sources account for a large part of $\mathrm{SO}_{2}$ emissions, whereas $\mathrm{NO}_{\mathrm{x}}$ and $\mathrm{O}_{3}$ depend more on traffic emissions. Also, since $\mathrm{SO}_{2}$ is not a very reactive species, the plume-in-grid impact can be carried further downwind than for very reactive species (see Sect. 4.2).

\subsubsection{Results on stations}

Although the impact of plume-in-grid on the global statistics is not very large, the local impact on stations can be significant, especially for stations situated downwind of large point sources. Figure 5 shows the decrease in RMSE, station per station, due to the plume-in-grid treatment of emissions. 


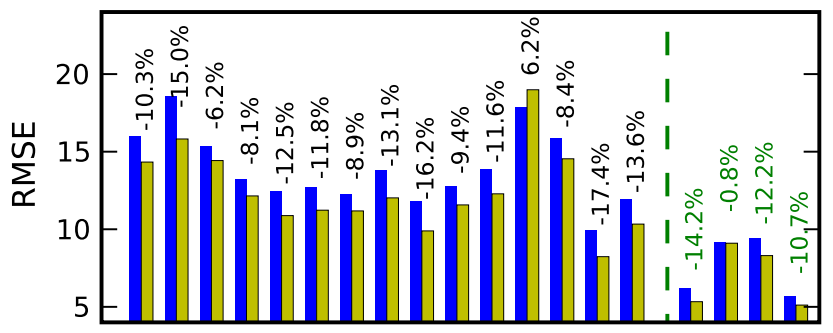

(a) $\mathrm{SO}_{2}$

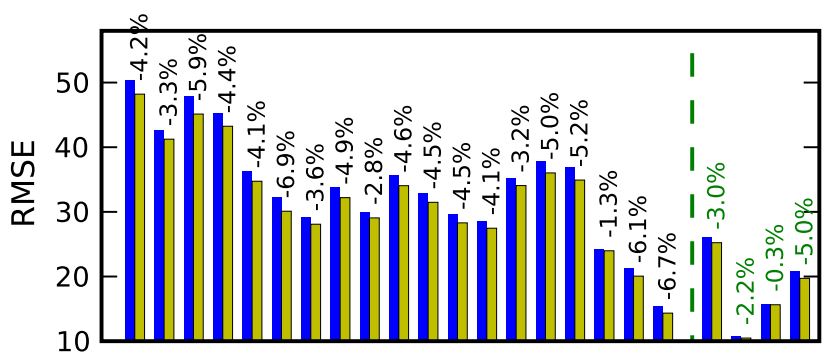

(b) $\mathrm{NO}$

Fig. 5. RMSE $\left(\mu \mathrm{g} \mathrm{m}^{-3}\right.$ ) at stations for the whole period (AprilSeptember), for reference model (blue, first bar) and plume-in-grid model with similarity theory (yellow, second bar). The difference between the plume-in-grid and reference RMSE is indicated above the bars for each station, in percent. The first group of bars is for urban stations (percent indicated in black), the second group is for periurban and rural stations (percent in green).

Here, the parameterization used for the plume-in-grid configuration is similarity theory. Similarly good results (not shown here) were also found with the Briggs parameterization. The RMSE decrease ranges from $6.2 \%$ to $17.4 \%$ for $\mathrm{SO}_{2}$, and from $1.3 \%$ to $6.9 \%$ for $\mathrm{NO}$, at urban stations. The results for periurban and rural stations are shown separately from the urban results. These stations are less influenced by traffic emissions, so the impact of point sources may be higher. However, they are farther from the sources than the urban stations. The overall RMSE on six months does show a significant impact at these stations, but no higher than the urban values. However, on particular days when the wind direction is such that one of these stations is downwind of the neighboring sources, the plume-in-grid impact is much higher (Sect. 4.2.2).

The results for $\mathrm{NO}_{2}$ and $\mathrm{O}_{3}$ are not shown, since the impact at particular stations was smaller, and well distributed among the stations: the RMSE for $\mathrm{O}_{3}$ decreases by $0.2 \%$ to $2 \%$, while the RMSE for $\mathrm{NO}_{2}$ increases by about the same amount.

\subsection{Spatial variability}

In this section, we assess how the impact of a subgrid treatment of emissions is spatially distributed. The plume-in-grid

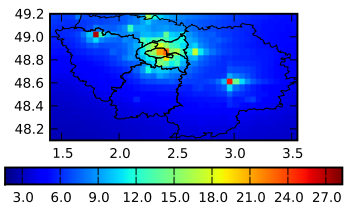

(a) $\mathrm{SO}_{2}-$ Reference

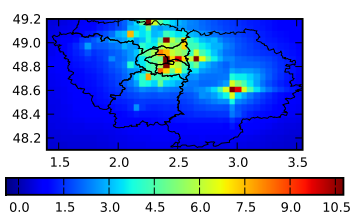

(c) $\mathrm{SO}_{2}$ - Reference - background

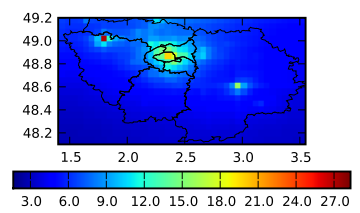

(b) $\mathrm{SO}_{2}$ - Plume-in-grid

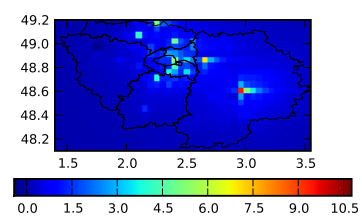

(d) $\mathrm{SO}_{2}$ - Reference - plume-in-grid
Fig. 6. $\mathrm{SO}_{2}$ concentrations over Paris region averaged over the simulation period, at ground level. (a) and (b) show the concentrations for the reference and the plume-in-grid simulation, respectively, in $\mu \mathrm{g} \mathrm{m}^{-3}$. (c) shows the differences between mean ground concentrations with and without point sources for the reference simulation. (d) shows the differences between mean ground concentrations with and without plume-in-grid treatment.

simulation used henceforth is the similarity-theory simulation, which gave the best results in Sect. 4.1.

\subsubsection{Impact on averaged concentrations}

Figure 6 shows the ground concentrations averaged over the whole simulation period for $\mathrm{SO}_{2}$. Figure $6 \mathrm{a}$ and $\mathrm{b}$ shows the mean ground concentrations for the reference simulation, and for the plume-in-grid simulation with similarity theory, respectively. Figure $6 \mathrm{c}$ shows the differences between reference and background simulations (i.e., the influence of the 89 point sources), and Fig. 6d gives the differences between reference and the plume-in-grid simulation (i.e., the impact of the advanced plume treatment). The use of a plume-in-grid treatment lowers the concentrations of the emitted species at the point sources locations. In most cases, the selected point sources are elevated, often at the second Eulerian vertical level (between $50 \mathrm{~m}$ and $150 \mathrm{~m}$ ) and sometimes in the third (above $150 \mathrm{~m}$ ). The plume-in-grid model maintains the plume higher than the Eulerian model, and it touches the ground later. Therefore, the concentrations are lower at the ground level near the source. Further downwind, when the plume touches the ground, the concentrations may be higher with the plume-in-grid treatment. However, we analyze an average value over a long time period, so there is no clear downwind direction to observe such a phenomenon. For near-ground sources, the plume-in-grid treatment may also result in lower concentrations, since the vertical diffusion is locally increased during daytime (Korsakissok and Mallet, 2010). For these reasons, the mean $\mathrm{SO}_{2}$ concentrations with plume-in-grid are globally lower. The impact of point sources treated with the plume-in-grid model is also more 


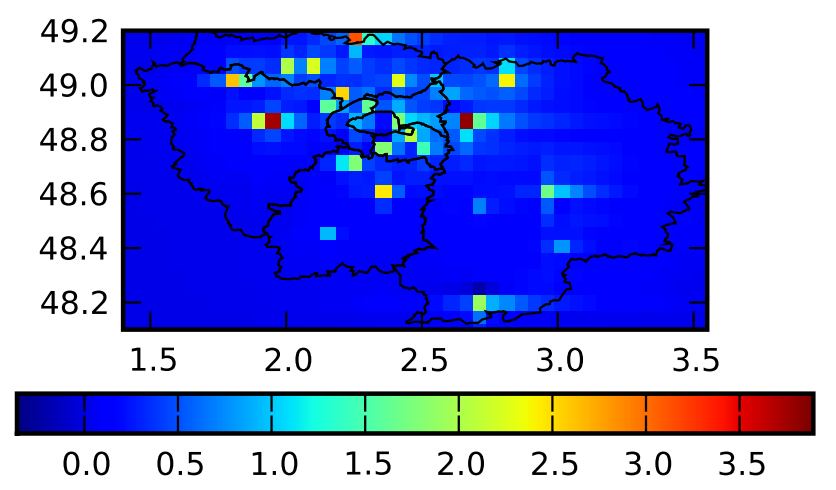

(a) $\mathrm{NO}_{2}$ - Reference - plume-in-grid

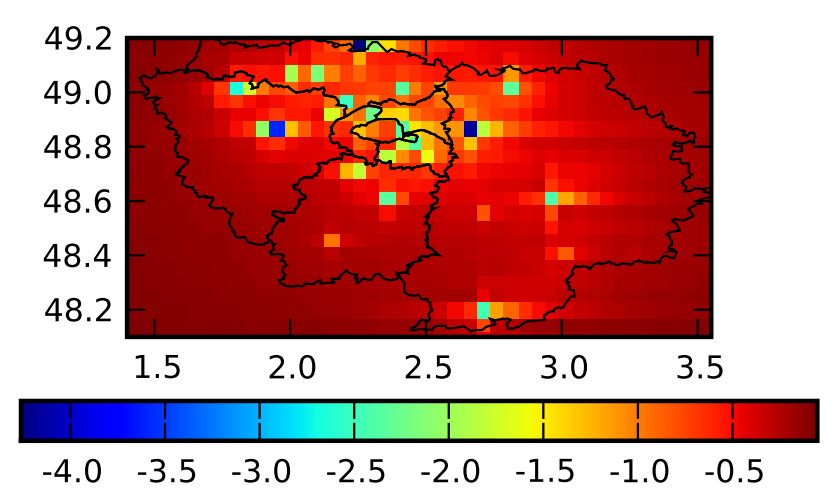

(b) $\mathrm{O}_{3}-$ Reference - plume-in-grid

Fig. 7. $\mathrm{NO}_{2}$ and $\mathrm{O}_{3}$ concentrations over Paris region averaged over the simulation period, at ground level, in $\mu \mathrm{g} \mathrm{m}^{-3}$. (a) shows the differences between mean ground concentrations with and without subgrid treatment for $\mathrm{NO}_{2}$. (b) shows the differences between mean ground concentrations with and without plume-in-grid treatment for $\mathrm{O}_{3}$.

localized around the sources locations, since there is less horizontal diffusion.

Figure 6a shows two main $\mathrm{SO}_{2}$ emission locations (except the urban area, at the center of the domain): at the north-west and south-east parts of the simulation domain. The northwestern location is not due to point sources (there are no differences in that area when excluding point sources of the simulation - see Fig. 6c). The point source with the highest emission rate is located in the south-east part of the domain (see Fig. 3), which is also clearly shown by Fig. 6c. This is also where the use of the plume-in-grid model has the most impact, as shown in Fig. 6d. Here, the source height is about $80 \mathrm{~m}$, so the plume stays higher with the plume-in-grid model, inducing lower ground concentrations.

The use of plume-in-grid also tends to lower the ground concentrations of $\mathrm{NO}$ and $\mathrm{NO}_{2}$ at point sources locations.
Figure 7 shows the results for $\mathrm{NO}_{2}$ and $\mathrm{O}_{3}$ concentrations. The ground concentrations of $\mathrm{O}_{3}$ are higher with the plumein-grid treatment. This comes from the titration of background $\mathrm{O}_{3}$ by the $\mathrm{NO}$ emissions from point sources. Since the plume-in-grid treatment for $\mathrm{NO}_{\mathrm{x}}$ sources infers lower $\mathrm{NO}_{\mathrm{x}}$ concentrations, it also results in slightly higher concentrations of $\mathrm{O}_{3}$ at ground level (there is less titration).

\subsubsection{Results for particular days}

We now analyze the particular case of a few specific days, in order to infer whether the impact of a subgrid-scale treatment for emissions depends on the meteorological situation. The first variable or influence is, of course, the wind direction: stations may locally significantly be impacted when situated downwind of sources. Moreover, the plume-in-grid impact may be more important during low-dispersion cases, when the Eulerian model significantly over-estimates the horizontal plume dilution. For primary pollutants, we selected two consecutive days, when the wind direction was such that several stations were downwind of the main sources: 23 and 24 August 2001. During these days, the wind speed ranged from $0.4 \mathrm{~m} \mathrm{~s}^{-1}$ to $2.6 \mathrm{~m} \mathrm{~s}^{-1}$, and the averaged boundary layer height was $600 \mathrm{~m}$. Those are typical values for lowdispersion days when concentrations of primary pollutants are higher than usual.

Figure 8 shows the evolution of the difference between reference and plume-in-grid ground concentrations for $\mathrm{SO}_{2}$, during twelve hours on 23 August. The maps show the hourly concentrations, from 03:00 (local hour) to 14:00 the same day. During these hours, the wind direction turns, and the wind speed decreases. In the first seven maps, the southeast source plume is clearly seen, and the plume-in-grid effect on this plume is to lower the concentrations (the differences are positive). The plume direction is south-southwest and clearly impacts some stations (especially the station "MELUN"; station $s 23$ on the Fig. 3). Another plume is visible in these first figures, located in the center-south of the domain. In this plume also, the plume-in-grid concentrations are much lower than the reference concentrations. In the last five maps, the situation is very stable, with a very low wind speed (around $0.5 \mathrm{~m} \mathrm{~s}^{-1}$ ), and concentrations are very high. In the plume-in-grid model, the puffs do not travel very far from the source before being transferred into the Eulerian model ( $600 \mathrm{~m}$ for an injection time of $20 \mathrm{~min}$ ). The concentrations simulated by the plume-in-grid model are particularly high during such low-dispersion episodes, since there is no artificial dilution as in the Eulerian model. When the puffs are transferred in the Eulerian model and touch the ground, downwind of the sources, it thus induces higher ground concentrations (differences are negative).

Figure 9 shows the $\mathrm{SO}_{2}$ profiles at six stations during the two days. The reference and plume-in-grid simulation with similarity theory are compared to the observations. The first station, MELUN, is a rural station which 

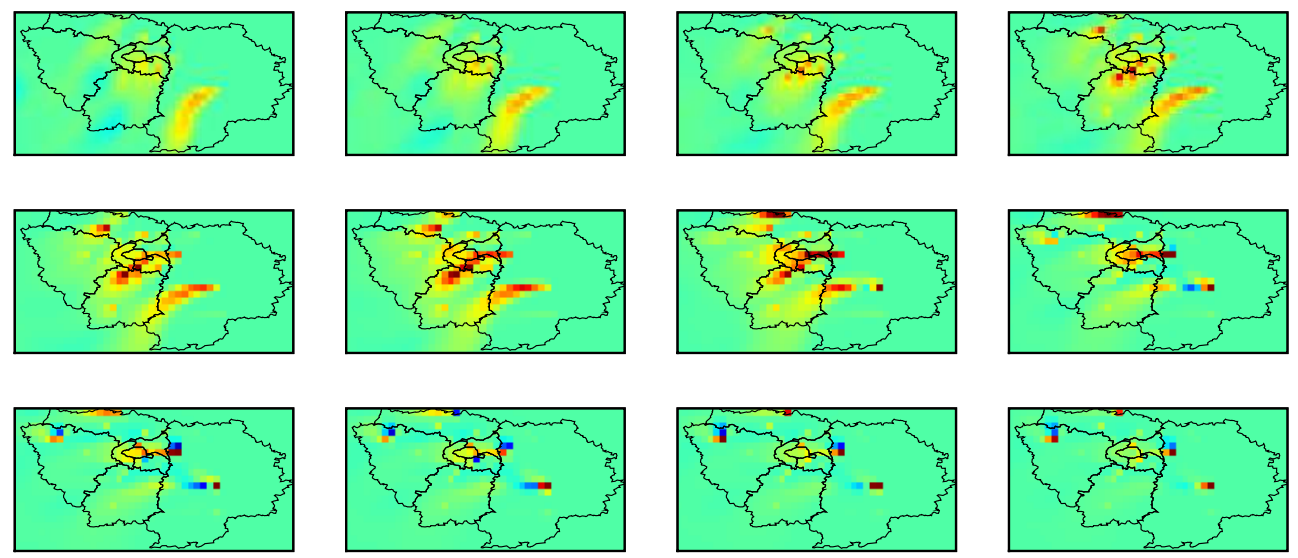

-20.1-17.6-15.1-12.6-10.1-7.6 -5.1 -2.6 -0.1 $2.4 \begin{array}{lllllll}4.9 & 7.5 & 10.0 & 12.515 .017 .520 .022 .525 .0\end{array}$

Fig. 8. Evolution of the difference between reference and plume-in-grid $\mathrm{SO}_{2}$ ground concentrations during twelve hours, from 23 August at 03:00 (local hour) to 23 August at 14:00. Unit is $\mu \mathrm{g} \mathrm{m}^{-3}$. Plume-in-grid concentrations are subtracted to the reference concentrations.
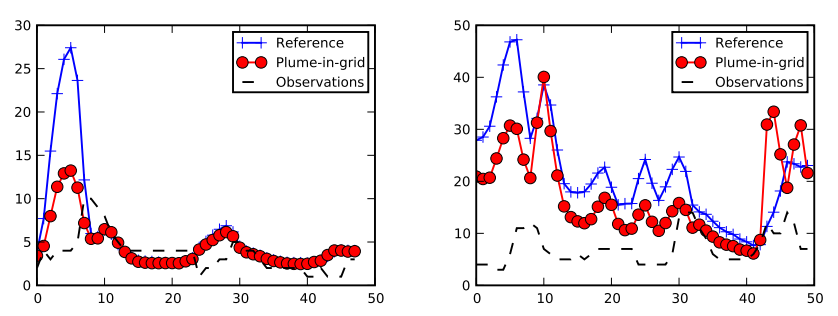

(a) MELUN

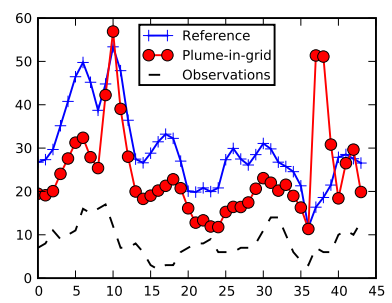

(c) IVRY-SUR-SEINE

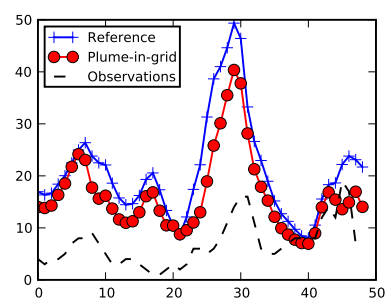

(e) AUBERVILLIERS (b) VITRY-SUR-SEINE

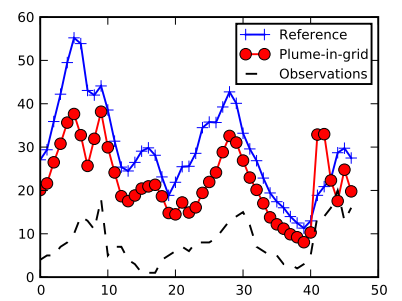

(d) PARIS12eme

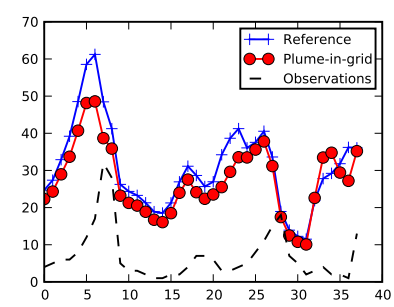

(f) LADEFENSE

Fig. 9. $\mathrm{SO}_{2}$ profiles during two days, from 2001-08-23 at 03:00 (local time) to 2001-08-25 at the same hour, at six stations. Profiles are shown for the measurement, reference simulation and plume-ingrid simulation with similarity theory.

is impacted by the south-east plume at the beginning of the period. In the remaining period, the measured concentrations are globally low. The plume-in-grid treatment induces less over-estimation of the plume impact, but does not modify the arrival time: even though the plume-in-grid treatment delays the plume arrival, it is negligible on hourlyaveraged concentrations. The next three stations, VITRYSUR-SEINE, IVRY-SUR-SEINE and PARIS12eme are situated in the southern part of Paris (which is in the middle of the simulation domain), within the second plume observed in Fig. 8. Here, the plume-in-grid profiles are much closer to the observations than the reference values. Finally, two stations situated in the northern part of Paris are also shown, since they are upwind of the main sources: the plume-in-grid impact is much lower at these stations, but still beneficial to the performance. The observed concentrations of $\mathrm{SO}_{2}$ are much lower than the simulated values. Since only the mean emission rate over the year is available for all sources, they are assumed to be continuously emitting, and the same temporal profile is applied to all of them. This is an approximation, since some of the main point sources are thermal power plants, which are only emitting during some periods. This leads to uncertainties and over-estimation of the emissions during some days, especially in summertime when many of these power plants are shut down.

The NO emissions are more concentrated within the urban area of Paris. Thus, the decrease in the NO concentration due to the plume-in-grid model is strong in the center of the domain (Fig. 10). The "touch-down" effect cannot clearly be seen, since there are many plumes within a small area. The effect of plume-in-grid is also very localized, since most of the emitted NO is chemically transformed at a relative short distance from the source. Although the differences are high, they are relatively small compared to the mean 

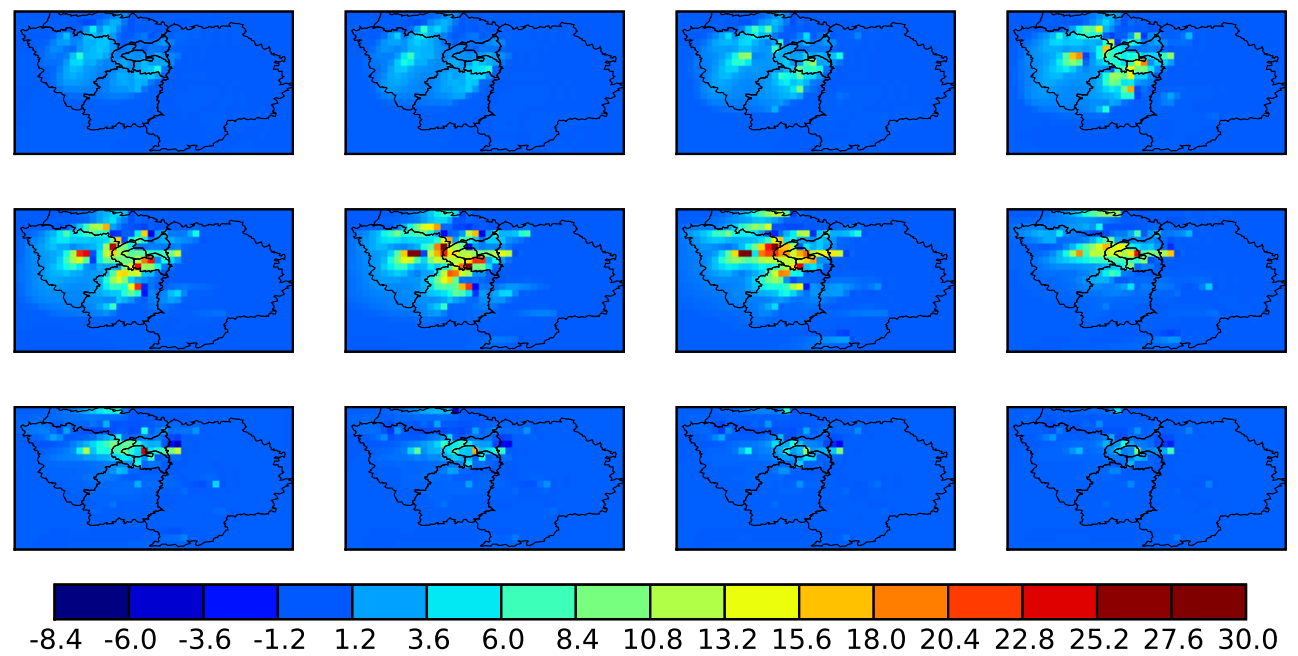

Fig. 10. Evolution of the difference between reference and plume-in-grid NO ground concentrations during twelve hours, from 23 August at 03:00 (local hour) to 23 August at 14:00. Unit is $\mu \mathrm{g} \mathrm{m} \mathrm{m}^{-3}$. Plume-in-grid concentrations are subtracted to the reference concentrations.
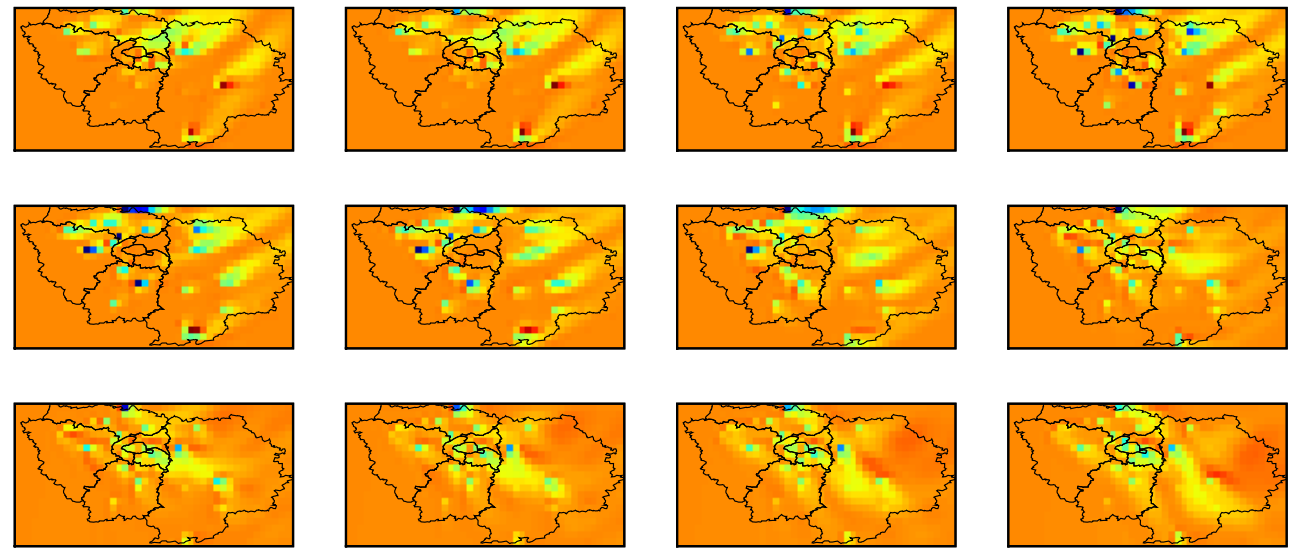

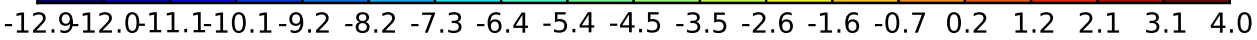

Fig. 11. Evolution of the difference between reference and plume-in-grid $\mathrm{O}_{3}$ ground concentrations during twelve hours, from 20 August at 03:00 (local hour) to 20 August at 14:00. Unit is $\mu \mathrm{g} \mathrm{m}^{-3}$. Plume-in-grid concentrations are subtracted to the reference concentrations.

concentrations, since $\mathrm{NO}$ emissions are mainly due to traffic. Thus, no significant differences are observed on the stations profiles (not shown). It should also be noticed that for NO as well as for $\mathrm{SO}_{2}$, the differences are larger during the morning (second row of maps on Figs. 8 and 10). During this period, concentrations are higher, since emissions are high and the boundary layer is not fully developed yet, leading to less vertical mixing than during the rest of the day. This is not specific to these particular days.

To study $\mathrm{O}_{3}$, the selected day is the 20 August. It is a day of low to medium dispersion, with a wind speed between 1 and $2 \mathrm{~m} \mathrm{~s}^{-1}$. This date is retained because the plume-in-grid impact is widely spread, and differences in ozone concentrations are transported over large distances. The effect of the plume-in-grid model is mainly to increase the $\mathrm{O}_{3}$ concentrations, as already explained in Sect. 4.2, but there are also some locations where $\mathrm{O}_{3}$ concentrations are clearly decreased. This may be due to the "touch-down" of the plume: in the plume-in-grid model, titration occurs within the plume held aloft, leading to a decrease in $\mathrm{O}_{3}$ concentrations when the plume touches the ground. It can also come from discrepancies between the wind directions within the first two vertical layers. Further downwind (outside the modeling domain), where the chemical regime may become $\mathrm{NO}_{\mathrm{x}}$-limited, the differences might become negative again due to the ozone production, as shown for instance in Vijayaraghavan et al. (2006). This particular day shows that the differences in $\mathrm{O}_{3}$ concentrations may be transported within some distance, and 


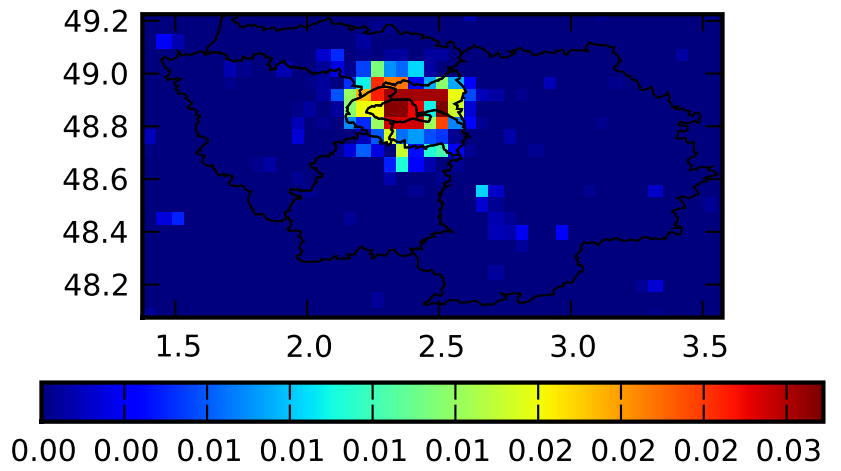

Fig. 12. Mean differences between $K_{z}$ values at $50 \mathrm{~m}$ with and without the minimum urban value of $K_{z \min }=0.5 \mathrm{~m}^{2} \mathrm{~s}^{-1}$. Diffusion coefficients are averaged over six months.

are less localized than the differences on the primary pollutants. This impact is not seen on the measurement stations, since they are all located within the urban area - at the center of the domain - whereas the $\mathrm{O}_{3}$ impact occurs mostly downwind of the urban plume, in rural areas.

\section{Sensitivity analysis}

\subsection{Influence of vertical diffusion}

\subsubsection{Urban vertical diffusion}

As explained in Sect. 3.1, when computing $K_{z}$ fields with the Troen-Mahrt parameterization, a minimum value is used in order to ensure a minimum vertical diffusion everywhere. In rural areas, it is set to $K_{z \min }=0.2 \mathrm{~m}^{2} \mathrm{~s}^{-1}$. In urban areas, however, the vertical diffusion is increased, due to the turbulence induced by heat and the particular radiative property of the urban canopy. Thus, the minimum value is increased for these areas, and set to $K_{z \min }=0.5 \mathrm{~m}^{2} \mathrm{~s}^{-1}$. This value is mostly activated during nighttime and very stable situations. Figure 12 shows the mean differences over six months, between vertical coefficient values at $50 \mathrm{~m}$, with and without the minimum urban value of $K_{z \min }=0.5 \mathrm{~m}^{2} \mathrm{~s}^{-1}$. In this section, the impact of such a change on the simulation results is assessed.

The results are shown for three simulations: (1) a simulation with the Eulerian model, and $K_{z_{\min }}=0.2 \mathrm{~m}^{2} \mathrm{~s}^{-1} \mathrm{ev}-$ erywhere (labeled " $K_{z}$ "), (2) a simulation with the Eulerian model, and $K_{z \min }=0.5 \mathrm{~m}^{2} \mathrm{~s}^{-1}$ over urban areas (labeled " $K_{z}$ urban") and (3) simulation with the plume-in-grid treatment for point sources, and $K_{z \min }=0.5 \mathrm{~m}^{2} \mathrm{~s}^{-1}$ over urban areas (labeled "plume-in-grid"). The simulations (2) and (3) are the reference simulation and the plume-in-grid simulation with similarity theory, respectively - they are the same as those already analyzed in Sect. 4. Table 2 shows the same statistical metrics as Table 1, for all species and for six months (1 April 2001-27 September 2001). Increasing the
Table 2. Hourly statistics: comparison between (1) the simulation with the Eulerian model and a uniform minimal value for $K_{z \min }$, (2) the reference simulation, that is, the Eulerian model with a specific value for $K_{z \min }$ in urban areas, and (3) the plume-in-grid results with similarity theory. The simulation period is 2001-04-01-200109-27. The best statistics are highlighted in bold.

\begin{tabular}{|c|c|c|c|c|}
\hline Statistic & Obs & $K_{z}$ & $K_{z}$ urban & plume-in-grid \\
\hline \multicolumn{5}{|l|}{$\mathrm{SO}_{2}$} \\
\hline Mean $\left(\mu \mathrm{g} \mathrm{m}^{-3}\right)$ & 6.20 & 13.95 & 13.76 & 11.98 \\
\hline RMSE & & 13.61 & 13.08 & 11.88 \\
\hline Correlation & & 0.35 & 0.34 & 0.31 \\
\hline MFBE & & 0.66 & 0.65 & 0.55 \\
\hline MFGE & & 0.81 & 0.81 & 0.75 \\
\hline \multicolumn{5}{|l|}{ NO } \\
\hline Mean $\left(\mu \mathrm{g} \mathrm{m}^{-3}\right)$ & 10.42 & 21.72 & 20.93 & 19.64 \\
\hline RMSE & & 35.34 & 33.08 & 31.62 \\
\hline Correlation & & 0.48 & 0.47 & 0.46 \\
\hline MFBE & & 0.42 & 0.41 & 0.36 \\
\hline MFGE & & 0.94 & 0.94 & 0.92 \\
\hline \multicolumn{5}{|l|}{$\mathrm{O}_{3}$} \\
\hline Mean $\left(\mu \mathrm{g} \mathrm{m}^{-3}\right)$ & 56.87 & 40.18 & 40.24 & 41.05 \\
\hline RMSE & & 30.58 & 30.58 & 30.18 \\
\hline Correlation & & 0.68 & 0.68 & 0.68 \\
\hline MFBE & & -0.46 & -0.46 & -0.44 \\
\hline MFGE & & 0.47 & 0.47 & 0.45 \\
\hline MNBE & & -0.34 & -0.34 & -0.33 \\
\hline MNGE & & 0.35 & 0.35 & 0.34 \\
\hline UPA & & -0.21 & -0.21 & -0.20 \\
\hline \multicolumn{5}{|l|}{$\mathrm{NO}_{2}$} \\
\hline Mean $\left(\mu \mathrm{g} \mathrm{m}^{-3}\right)$ & 34.64 & 36.04 & 35.84 & 35.23 \\
\hline RMSE & & 20.65 & 20.57 & 20.81 \\
\hline Correlation & & 0.58 & 0.58 & 0.57 \\
\hline MFBE & & 0.07 & 0.06 & 0.04 \\
\hline MFGE & & 0.47 & 0.47 & 0.47 \\
\hline
\end{tabular}

vertical diffusion in urban areas improves the overall statistics by reducing the over-estimation of emitted species. As in the case of plume-in-grid, the secondary pollutants, especially $\mathrm{O}_{3}$, are less sensitive to the model configuration than the primary pollutants, since vertical gradients are smaller. The most impacted species is NO, which can be explained by the strong vertical concentration gradient for this species, with higher concentration at ground level due to traffic emissions. Thus, increasing the vertical diffusion tends to lower NO ground concentrations.

\subsubsection{Eulerian and Gaussian vertical diffusion}

In theory, Gaussian models allow to better represent the nearsource diffusion than the K-theory used in Eulerian models. This effect was shown in Korsakissok and Mallet (2010), on a case with a single near-ground source and neutral to stable meteorological situation, where the vertical diffusion was enhanced by the plume-in-grid model. In the present study, it was shown in Table 1 that similarity-theory parameterization 
Table 3. Hourly statistics: comparison between (1) Base simulation: plume-in-grid with similarity theory, $t_{\text {inj }}=20 \mathrm{~min}$ and $\Delta t_{\text {puff }}=100 \mathrm{~s}$, (2) plume-in-grid with similarity theory and $\Delta t_{\text {puff }}=600 \mathrm{~s}$, (3) plume-in-grid with similarity theory and $t_{\text {inj }}=40 \mathrm{~min}$. The simulation period is 2001-04-01-2001-09-27. The best statistics are highlighted in bold.

\begin{tabular}{lcccc}
\hline Statistic & Obs & Base & $\Delta t_{\text {puff }}=600 \mathrm{~s}$ & $t_{\text {inj }}=40 \mathrm{~min}$ \\
\hline $\mathrm{SO}_{2}$ & & & & \\
Mean $\left(\mu \mathrm{g} \mathrm{m}^{-3}\right)$ & 6.20 & 11.98 & 11.98 & $\mathbf{1 1 . 8 6}$ \\
RMSE & & 11.88 & 11.87 & $\mathbf{1 1 . 5 7}$ \\
Correlation & & 0.31 & 0.31 & $\mathbf{0 . 3 2}$ \\
MFBE & & 0.55 & 0.55 & $\mathbf{0 . 5 4}$ \\
MFGE & & $\mathbf{0 . 7 5}$ & $\mathbf{0 . 7 5}$ & $\mathbf{0 . 7 5}$ \\
NO & & & \\
Mean $\left(\mu \mathrm{g} \mathrm{m}^{-3}\right)$ & 10.42 & 19.64 & 19.59 & $\mathbf{1 9 . 5 6}$ \\
RMSE & & 31.62 & 31.60 & $\mathbf{3 1 . 5 2}$ \\
Correlation & & $\mathbf{0 . 4 6}$ & $\mathbf{0 . 4 6}$ & $\mathbf{0 . 4 6}$ \\
MFBE & & 0.36 & $\mathbf{0 . 3 4}$ & 0.36 \\
MFGE & & $\mathbf{0 . 9 2}$ & 0.93 & $\mathbf{0 . 9 2}$ \\
O3 & & & \\
Mean $\left(\mu \mathrm{g} \mathrm{m}^{-3}\right)$ & 56.87 & 41.05 & 40.87 & $\mathbf{4 1 . 0 9}$ \\
RMSE & & 30.18 & 30.25 & $\mathbf{3 0 . 1 7}$ \\
Correlation & & $\mathbf{0 . 6 8}$ & $\mathbf{0 . 6 8}$ & $\mathbf{0 . 6 8}$ \\
MFBE & & $-\mathbf{0 . 4 4}$ & -0.45 & $-\mathbf{0 . 4 4}$ \\
MFGE & & $\mathbf{0 . 4 5}$ & 0.46 & $\mathbf{0 . 4 5}$ \\
MNBE & & $\mathbf{- 0 . 3 3}$ & $-\mathbf{0 . 3 3}$ & $\mathbf{- 0 . 3 3}$ \\
MNGE & & $\mathbf{0 . 3 4}$ & $\mathbf{0 . 3 4}$ & $\mathbf{0 . 3 4}$ \\
UPA & & $-\mathbf{0 . 2 0}$ & $-\mathbf{0 . 2 0}$ & $\mathbf{- 0 . 2 0}$ \\
NO & & & \\
Mean $\left(\mu \mathrm{g} \mathrm{m}^{-3}\right.$ ) & 34.64 & 35.23 & 35.32 & $\mathbf{3 5 . 2 2}$ \\
RMSE & & 20.81 & 20.81 & $\mathbf{2 0 . 8 0}$ \\
Correlation & & $\mathbf{0 . 5 7}$ & $\mathbf{0 . 5 7}$ & $\mathbf{0 . 5 7}$ \\
MFBE & & $\mathbf{0 . 0 4}$ & $\mathbf{0 . 0 4}$ & $\mathbf{0 . 0 4}$ \\
MFGE & & $\mathbf{0 . 4 7}$ & $\mathbf{0 . 4 7}$ & $\mathbf{0 . 4 7}$ \\
\hline
\end{tabular}

for Gaussian standard deviations gives better results than Briggs' or Doury's formulas, although the estimates of vertical diffusion given by the last two formulas are generally higher. In particular, when more than a quarter of the cell is urban, Briggs' formulas are automatically switched from rural to urban formulas, which give a much larger vertical diffusion. However, overall results with Briggs formulas are not quite as good as with similarity-theory parameterization. This may be due to a compensating effect between rural and urban plumes that impact a given station, depending on a meteorological situation. Besides, most of the point sources treated by the plume-in-grid model in this study are elevated sources (second or third vertical level). Thus, the main effect of the plume-in-grid treatment is to hold the plume aloft for a longer time period, and the enhanced vertical diffusion is not as important as for near-ground sources.

\subsection{Influence of local-scale modeling}

The "local scale" refers to the characteristic scale where the subgrid modeling of sources occur. It is the near-source area where the Gaussian puff model is used, and it is determined by the choice of the injection criterion (Sect. 2.2). The impact of the standard deviation parameterizations has already been addressed. In this section, the sensitivity to two other parameters is analyzed: the injection time $t_{\mathrm{inj}}$ and the time step between two puffs $\Delta t_{\text {puff. }}$. Hereafter, the "base" simulation refers to the plume-in-grid simulation with similarity theory used in the previous parts of the study. For that base case, $t_{\text {inj }}=20 \mathrm{~min}$ and $\Delta t_{\text {puff }}=100 \mathrm{~s}$.

Table 3 gives the global statistics for the base simulation (already shown), as well as for the simulations with (1) a larger time step between two puffs $\left(\Delta t_{\text {puff }}=600 \mathrm{~s}\right)$ and (2) a larger injection time $\left(t_{\text {inj }}=40 \mathrm{~min}\right)$. Increasing the time step between two puffs does not significantly change the results. $\mathrm{SO}_{2}$ is fairly insensitive to that parameter. The results for the reactive species are slightly different from the base results: worse for $\mathrm{O}_{3}$ and $\mathrm{NO}_{2}$, and better for $\mathrm{NO}$. The time step between two puffs is important for reactive species, since it determines the overlap volume between two consecutive puffs. If this time step is not sufficient, the overlap volume between two consecutive puffs is small during the first time steps. On the other hand, each puff contains a larger amount of quantity: the quantity for each puff is given by $Q=Q_{s} \times \Delta t_{\text {puff }}$, where $Q_{s}$ is the source rate in mass unit per second, for a given species. As a result, the chemistry within each puff is enhanced. In the case of $\mathrm{NO}_{\mathrm{x}}$ and $\mathrm{O}_{3}$ chemistry, this leads to slightly more titration, which means a decrease in $\mathrm{NO}$ and $\mathrm{O}_{3}$ concentrations, and an increase of $\mathrm{NO}_{2}$ concentrations. The impact of this phenomenon is not very large, but not negligible compared to the global plume-in-grid impact for these species.

The injection time has much more influence on $\mathrm{SO}_{2}$ than on the reactive species. Using the Gaussian puff model for a longer time allows to widen the scope of the plume-in-grid impact, thus improving the results for $\mathrm{SO}_{2}$. Compared to the base case (plume-in-grid with $t_{\text {inj }}=20 \mathrm{~min}$ ), the RMSE on urban stations are improved by $0.4 \%$ to $8 \%$, with an improvement at most stations around $2 \%$. This is an additional improvement, compared to the initial difference brought by the base case (in Fig. 5). The impact on NO results, however, is not so large: the global statistics are not significantly modified, and the highest improvement on stations is $0.8 \%$. The results for $\mathrm{NO}_{2}$ and $\mathrm{O}_{3}$ are still less impacted. Thus, for reactive species, increasing the injection time is not a major improvement: after some time, the plume composition becomes closer to the background composition, and the plume-in-grid treatment induces less additional differences.

Figure 13 summarizes the sensitivity analysis made in this section, along with the impact of vertical diffusion. It is shown for $\mathrm{SO}_{2}, \mathrm{NO}_{\mathrm{x}}$ and $\mathrm{O}_{3}$. This figure shows that each species is mostly sensitive to a different parameter: $\mathrm{SO}_{2}$ 


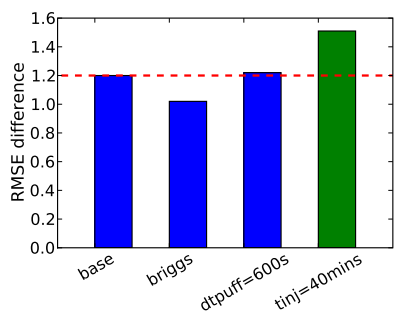

(a) $\mathrm{SO}_{2}$

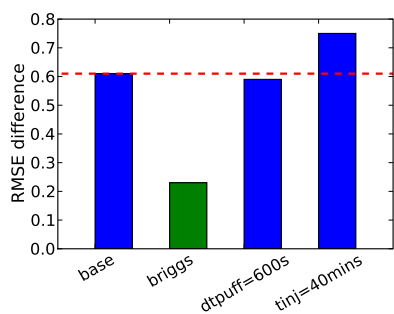

(b) $\mathrm{NO}_{\mathrm{x}}$

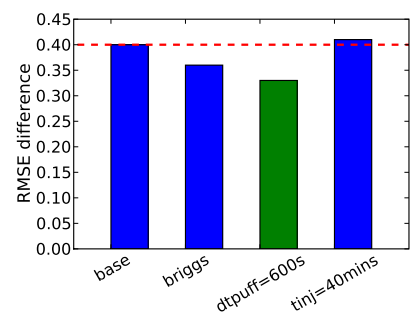

(c) $\mathrm{O}_{3}$

Fig. 13. Differences (Polair3D - plume-in-grid) in $\operatorname{RMSE}\left(\mu \mathrm{g} \mathrm{m}^{-3}\right)$, computed on all stations and six months for $\mathrm{SO}_{2}, \mathrm{NO}_{\mathrm{x}}$ and $\mathrm{O}_{3}$. (1) "base": plume-in-grid with similarity theory, $t_{\text {inj }}=20$ minutes and $\Delta t_{\text {puff }}=100 \mathrm{~s}$, (2) "briggs": base case with Briggs formulas instead of similarity theory, (3) base case with $\Delta t_{\text {puff }}=600 \mathrm{~s}$, (4) base case with $t_{\text {inj }}=40$ minutes. Dotted line : base results. Green bars correspond to the highest sensitivity for each species.

is sensitive to the injection time, $\mathrm{NO}_{\mathrm{x}}$ to the diffusion parameterization, and $\mathrm{O}_{3}$ is mostly impacted by the time step between two puffs. This illustrates the importance of carefully choosing all these parameters, depending on the target species and the computational time.

\section{Conclusions}

The plume-in-grid model implemented on the Polyphemus platform has been applied to regional photochemistry over Paris region. Model-to-data comparisons have been performed and compared to the results obtained when using the Eulerian model Polair3D alone. The plume-in-grid impact on the mean results for six months is not large, although significant for primary emitted species. This impact is higher when using the similarity-theory parameterization for standard deviations, which performs better than the other two parameterizations. With that scheme, the RMSEs at the stations are reduced by up to $17 \%$ in the case of $\mathrm{SO}_{2}$ and up to $7 \%$ for NO. The impact on $\mathrm{NO}_{2}$ and $\mathrm{O}_{3}$ is much smaller, since they are more influenced by traffic emissions than by point sources.

Using a plume-in-grid treatment for point emissions has a significant impact on the near-source concentrations. It may be carried up to some distance downwind, depending on the meteorological situation. Low-dispersion situations, when the Eulerian model significantly over-estimates the horizon- tal plume dilution, also increase the plume-in-grid benefit. This can be observed on the station profiles for particular days, when some measurement stations are located downwind of the main sources.

The effect of the plume-in-grid model is to lower the ground concentrations of emitted species, through two mechanisms: (1) the plume is held aloft longer than in the Eulerian model, and (2) the near-source vertical diffusion and chemistry are better represented. It results in higher $\mathrm{O}_{3}$ ground concentrations, since there is less titration. Further downwind, when the plume touches the ground, the reverse may be observed, as the titrated $\mathrm{O}_{3}$ plume is transported to the ground.

When addressing the sensitivity to the urban vertical diffusion, which is often under-estimated, the primary pollutants are again the most impacted species. The influence of two plume-in-grid parameters was also assessed. The time step between two puff emissions mostly influences the chemically reactive species - near-source chemical rates are slightly over-estimated when the time step is too large. On the contrary, the almost-passive species $\mathrm{SO}_{2}$ is mostly impacted by a change in the injection time. Since these two parameters determine the number of puffs handled by the model and the corresponding computational time, they must be carefully chosen according to the target species.

Future developments and applications of this model include an application at continental scale over Europe, and an extension to handle aerosol chemistry. In addition, the model will be extended to the modeling of line sources in order to use the subgrid-scale treatment with road emissions. This application is expected to show much more striking results, because of the importance of traffic emissions on the pollutants of interest. Another important point would be to include simplified in-plume chemistry, as described in Karamchandani et al. (1998), in order to significantly reduce the computational time for puffs chemistry. This would be particularly interesting since the plume-in-grid impact on secondary species is not very large.

\section{Appendix A}

\section{Overlapping puffs}

We consider that two puffs $\alpha$ and $\beta$ overlap if the distance between their centers is smaller than $2\left(\sigma_{j}^{\alpha}+\sigma_{j}^{\beta}\right)$ in one direction $j \in(x, y, z)$. We note $\left\langle c_{A}^{\alpha}\right\rangle$ the integral over space of the concentration of species $A$ in the puff $\alpha$. The quantity of species $A$ in puff $\alpha$ is thus $Q_{A}^{\alpha}=\left\langle c_{A}^{\alpha}\right\rangle$. We define the puff volume as

$V_{\alpha}=\frac{\left\langle c_{A}^{\alpha}\right\rangle^{2}}{\left\langle c_{A}^{\alpha}{ }^{2}\right\rangle}$.

Equation (A1) gives the definition of the puff's volume, since we have to use a finite volume in chemistry while in the case 
of Gaussian puffs, the "real" volume is infinite. This definition is verified in the case of puffs with a finite volume and a uniform concentration. Here, $c_{a}^{\alpha}$ is the product of gaussian shapes in the three directions, so the puff's volume can be computed as a function of the gaussian standard deviations

$V_{\alpha}=2^{3} \pi^{3 / 2} \sigma_{x}^{\alpha} \sigma_{y}^{\alpha} \sigma_{z}^{\alpha}$.

The overlap volume between two puffs $\alpha$ and $\beta$ is noted $V_{\alpha \beta}$ and defined as

$\frac{V_{\alpha \beta}}{V_{\alpha} V_{\beta}}=\frac{\left\langle c_{A}^{\alpha} c_{A}^{\beta}\right\rangle}{\left\langle c_{A}^{\alpha}\right\rangle\left\langle c_{A}^{\beta}\right\rangle}$.

Therefore, the quantity of species $A$ transported by the puff $\alpha$ is $Q_{A}^{\alpha}=V_{\alpha} \times c_{A}^{\alpha}$, and the quantity of species $A$ within the volume of puff $\alpha$, but coming from any overlapping puff $\beta$ is $Q_{A}^{\alpha \beta}=V_{\alpha \beta} \times c_{A}^{\beta}$. Hence, we define the overlap concentration of species $A$ and puff $\alpha$ as the total quantity of $A$ from all the overlapping puffs, diluted within the volume $V_{\alpha}$ (Eq. A4):

$\widehat{c_{A}^{\alpha}}=\sum_{\beta} Q_{A}^{\beta} \frac{V_{\alpha \beta}}{V_{\alpha} V_{\beta}}=\sum_{\beta} c_{A}^{\beta} \frac{V_{\alpha \beta}}{V_{\alpha}}$

The chemistry during a time step $\Delta t$ is computed with the overlap concentrations from all puffs. The overlap concentration at the end of the time step is then

$\widehat{c_{A}^{\alpha}}(t+\Delta t)=\widehat{c_{A}^{\alpha}}(t)+\Delta \widehat{c_{A}^{\alpha}}$.

However, the species produced within the overlap volumes are taken twice into account: once with the overlapping concentrations of puff $\alpha$, and once with those of puff $\beta$. The production (or loss) must be distributed into the two puffs to ensure the mass conservation. One option (Karamchandani et al., 2000) is to take

$\Delta Q_{A}^{\alpha}=\Delta \bar{c}_{A}^{\widehat{\alpha}} \times \frac{Q_{A}^{\alpha}(t)}{\widehat{c_{A}^{\alpha}}(t)}$

as the actual quantity of species $A$ created during $\Delta t$ in puff $\alpha$.

Acknowledgements. We thank Christian Seigneur for his help in the development of the puffs chemistry. We also thank Airparif for having provided the emission inventory and the observations, and Marilyne Tombette for providing the programs processing Airparif emissions.

Edited by: S. Galmarini

\section{References}

Boutahar, J., Lacour, S., Mallet, V., Quélo, D., Roustan, Y., and Sportisse, B.: Development and validation of a fully modular platform for numerical modelling of air pollution: POLAIR, Int. J. Env. Pollut., 22, 17-28, 2004.

Brandt, J.: Modelling Transport, Dispersion and Deposition of Passive Tracers from Accidental Releases, Ph.D. thesis, National Environmental Research Institute, 1998.

Chang, J. and Hanna, S.: Air quality model performance evaluation, Meteorol. Atmos. Phys., 87, 167-196, 2004.

EPA: Guideline for regulatory application of the urban airshed model, Tech. Rep. EPA-450/4-91-013, US EPA, 1991.

EPA: Guidance on the use of models and other analyses in attainment demonstrations for the 8-hr ozone NAAQS, Tech. Rep. EPA-450/R-99-004, US EPA, 2005.

Gillani, N.: Ozone formation in pollutant plumes: Development and application of a reactive plume model with arbitrary crosswind resolution, Tech. Rep. EPA-600/S3-86-051, US Environmental Protection Agency, Research Triangle Park, NC, USA, 1986.

Godowitch, J.: Simulations of aerosols and photochemical species with the CMAQ plume-in-grid modeling system, 3rd CMAS Models-3 Users' Conference, Univ. North Carolina, Chapel Hill, NC, USA, 2004.

Hanna, S. and Paine, R.: Hybrid Plume Dispersion Model (HPDM) Development and Evaluation, J. Appl. Meteor., 28, 206-224, 1989.

Karamchandani, P., Koo, A., and Seigneur, C.: Reduced gas-phase kinetics mechanism for atmospheric plume chemistry, Environ. Sci. Technol., 32, 1709-1720, 1998.

Karamchandani, P., Santos, L., Sykes, I., Zhang, Y., Tonne, C., and Seigneur, C.: Development and evaluation of a state-of-thescience reactive plume model, Environ. Sci. Technol., 34, 870880, 2000.

Karamchandani, P., Seigneur, C., Vijayaraghavan, K., and Wu, S.: Development and application of a state-of-the-science plumein-grid model, J. Geophys. Res., 107(D19), 4403, doi:10.1029/ 2002JD002123, 2002.

Korsakissok, I. and Mallet, V.: Comparative study of Gaussian dispersion formulas within the Polyphemus platform: evaluation with Prairie Grass and Kincaid experiments, J. Appl. Meteor., 48, 2459-2473, doi:10.1175/2009JAMC2160.1, 2009.

Korsakissok, I. and Mallet, V.: Subgrid-scale treatment for major point sources in an Eulerian model: a sensitivity study on the ETEX and Chernobyl cases, J. Geophys. Res., 115, D03303, doi: 10.1029/2009JD012734, 2010.

Kumar, N. and Russell, A.: Development of a computationally efficient, reactive subgrid-scale plume model and the impact in the northern United States using increasing levels of chemical details, J. Geophys. Res., 101, 16737-16744, 1996.

Louis, J.-F.: A parametric model of vertical eddy fluxes in the atmosphere, Bound.-Layer Meteor., 17, 187-202, 1979.

Mallet, V., Quélo, D., Sportisse, B., Ahmed de Biasi, M., Debry, É., Korsakissok, I., Wu, L., Roustan, Y., Sartelet, K., Tombette, M., and Foudhil, H.: Technical Note: The air quality modeling system Polyphemus, Atmos. Chem. Phys., 7, 5479-5487, 2007, http://www.atmos-chem-phys.net/7/5479/2007/.

Maryon, R. and Buckland, A.: Tropospheric dispersion: The first ten days after a puff release, Quart. J. Roy. Meteor. Soc., 121, 1799-1833, 1995. 
Morris, R., Yocke, M., Myers, T., and Kessler, R.: Development and testing of UAM-V: A nested-grid version of the Urban Airshed Model, in: Proceedings of the AWMA conference: Tropospheric ozone and the environment II, Pittsburgh, PA, USA, 1991.

Seigneur, C., Tesche, T., Roth, P., and Liu, M.: On the treatment of point source emissions in urban air quality modeling, Atmos. Environ., 17, 1655-1676, 1983.

Stockwell, W. R., Kirchner, F., Kuhn, M., and Seefeld, S.: A new mechanism for regional atmospheric chemistry modeling, J. Geophys. Res., 102, 25847-25879, 1997.

Taylor, G.: Diffusion by continuous movements, Proc. Lnd. Math. Soc., 20, 196-211, 1921.
Tombette, M. and Sportisse, B.: Aerosol modeling at a regional scale: Model-to-data comparison and sensitivity analysis over Greater Paris, Atmos. Environ., 41, 6941-6950, 2007.

Troen, I. and Mahrt, L.: A simple model of the atmospheric boundary layer; sensitivity to surface evaporation, Bound.-Layer Meteor., 37, 129-148, 1986.

Vijayaraghavan, K., Karamchandani, P., and Seigneur, C.: Plumein-grid modeling of summer air pollution in Central California, Atmos. Environ., 40, 5097-5109, 2006. 